\title{
Bilgi Çağında Yeni Bir Liderlik: Resonant (Ahenk Yaratan) Liderlik
}

DOI: $10.26466 /$ opus.580701

\begin{abstract}
$*$
Müslüme Akyüz *

* Dr. Öğr. Üyesi, Cumhuriyet Üniversitesi, Suşehri Sağlık Yüksek Okulu, Suşehri/Sivas, Türkiye E-Posta: muslumeakyuz@hotmail.com ORCID: 0000-0002-0922-6191

\section{Öz}

Bilgi çă̆ı yapısı itibariyle karmaşıklığın ve kompleks sorunların da yaşandığı bir süreci beraberinde getirmiştir. Tüm bu karmaşık ve kompleks sorunların çözümünde örgütlerin, geleneksel liderlik modellerinden farklı olarak yeni ve etkili liderlere ihtiyaçları vardır. Bu çalışmada da yeni bir liderlik modeli olarak karşımıza çıkan resonant (ahenk yaratan) liderlik kavramıla ilgili yerli ve yabancı literatürde yer alan kaynaklar incelenerek, kavramın sınırlarının çizilmesi amaçlanmıştır. Amaca yönelik olarak literatür taraması yöntemi kullanılmıştır. Resonant (ahenk yaratan) liderlik; duygusal zeka seviyesi yüksek, çevresiyle uyumlu, güçlü ve güvene dayalı ilişkiler kurabilen, sadece kendi duyguların değil, liderlik yaptığ 1 izleyenlerinin duygu ve düşüncelerini de kontrol edebilme gücüne sahip, empati yapabilen, tutkulu, kararll, umutlu, cesaretli, açık görüşlü, pozitif düşünce gücüne sahip, örgütleri doğru şekilde okuma becerisine sahip ve izleyenlerine ilham verebilen liderlik olarak tanımlamak mümkündür. Bu çalışma kapsamında resonant liderlik kavramı örgütsel açıdan ele alınarak resonant liderliğin özellikleri ve boyutları ele alınmıştır. Çalışmanın sonucunda, resonant liderliğin sadece bugünde değgil, gelecekte de kendine yer bulacak önemli bir liderlik tarzı olduğu belirlenmiştir.
\end{abstract}

Anahtar Kelimeler: Liderlik, Resonant liderlik, Örgüt 


\title{
A New Leadership on The Knowledge Age: Resonant Leadership
}

\begin{abstract}
Knowledge Age brought along a process if complication and complex problems by its structure. In solving all this complicated and complex problems, organizations need new and effective leaders, unlike traditional leadership models. In this study, it is aimed to draw the limits of the concept by examining the sources in the local and foreign literature about the concept of resonant leadership as a new leadership model. For this aim, literature search method has been used. Resonant leadership; it is possible to define it as having high level of emotional intelligence, beingcoherent with his/her environment, building strong and trustable relations, having power to control not only own feelings but also the feelings and thoughts of his followers, empathising, being passionate, determined, hopeful, courageous, open-minded, thinking positively, having the ability to read organizations correctly and inspiring his/her followers. Within the scope of the study, the characteristics and dimensions of resonant leadership is taken by discussing the concept of resonant leadership from the organizational aspect. As a result of the study, it has been determined that resonant leadership is an important leadership style which will find a place not only in the present but future.
\end{abstract}

Keywords: Leadership, Resonant Leadership, Organization 


\section{Giriş}

20. yüzyılın başlarından itibaren odak noktası haline gelmiş fenomenlerden biri olan ve (Dhammika, 2014, s.2), "ortak bir amaca ulaşmak için bir grup insanı etkileme süreci" (Northouse, 2010, s.12) olarak tanımlanan liderlik kavramı da diğer birçok kavram gibi günümüzdeki hızlı ve önlenemez değişimlerden büyük ölçüde etkilenmektedir. Özellikle günümüz bilgi çağında bu değişim; fiziksel sınırların ortadan kalkması, rekabet anlayışının değişmesi (Tokay, Deran ve Arslan, 2010, s.225), bilgi ve insan kaynağının etkin ve verimli kullanılması gerekliliğini ortaya koymuştur. Bu noktadan hareketle liderler ve izleyenleri arasındaki ilişki daha karmaşık hale gelmiştir (Taner, 2013, s.594).

Bilgi çağının gereksinimlerine de uygun olarak ortaya çıkan bu değişimler, liderlik ile ilgili geleneksel yaklaşımların yanında, yeniden şekillenen yeni liderlik yaklaşımları ortaya çıkarmıştır. Dolayısıyla liderlik kavramı zamanla farklı formlara girmiş ve klasik liderlik yaklaşımlarının ötesinde artık farklı bir seviyeye ulaşmıştır (Gelatt 2002). Bu yeni yaklaşımlardan biri de duygusal zekaya dayanan "resonant liderlik" dir. Resonant liderlik kavramı içerisinde farkındalık, umut ve merhameti barındırmaktadır. Bu üç kavram tüm liderlerde bulunması gereken özellikler olsa da resonant liderliği diğer liderlik türlerinden ayıran durum, liderlerin bu özellikleri duygusal zekalarını kullanarak yapabilmesidir (Lutzo, 2005; Taner, 2013, s.595).

Bu çalışmanın amacı da, sadece mantığı ile değil duyguları ile de hareket edebilen (Squires, Tourangeau, Lachinger, ve Doran, 2010, s.916), temeli duygusal zekaya dayanan, ilişki (bireye odaklanan bir yaklaşım şekli) odaklı (Goleman, Boyatzis, ve McKee, 2002) bir liderlik tarzı olan "resonant liderlik" kavramının ayrıntılı bir şekilde incelenmesidir. Belirlenen amaca uygun olarak, çalışmada liderlik ile ilgili literatür taranarak, 21. yüzyılın liderliğinin nasıl bir değişim gösterdiği liderlik yaklaşımları içerisinde resonant liderlik kavramının yeri, tanımı ve kavramın içeriği irdelenmiştir. Bu kapsamda, çalışmada resonant liderlik kavramı daha önce yapılan çalışmalar çerçevesinde bir bütün olarak ortaya koyulmaya çalışılmıştır. 


\section{Kavramsal Çerçeve}

\section{Liderlik Kavramı}

Toplumları etkileyen önemli olgulardan birisi olan liderliğin başlangıcı insanlık tarihi kadar eskilere dayanmaktadır. Liderlik, Platon'dan günümüze kadar pek çok araştırmacının ilgisini çeken konuların başında gelmiştir (Barutçugil, 2014, s.26). Kavram, özellikle 1920'li yılların başından itibaren bilime konu olmaya başlamış ve kavramın farklı yönlerinin ele alındığı pek çok tanımı yapılmıştır. Öyle ki sadece geçtiğimiz yüzyılda liderlik ile ilgili 5000'in üzerinde çalışma ve 350'den fazla da tanım ortaya koyulmuştur (Erçetin, 2000, s.3). Bu tanımlardan bazıları aşağıdaki tabloda verilmiştir.

Tablo 1. Liderlik Tanımları

\begin{tabular}{lll}
\hline Yıllar & Araştırmacılar & Liderlik tanımları \\
\hline 1902 & Cooley & Sosyal hareketlerin merkezinde olabilmektir. \\
\hline 1921 & Munson & $\begin{array}{l}\text { En az çatışma ve en etkili işbirliği ile insanları başarıya ulaş- } \\
\text { maktır. }\end{array}$ \\
\hline 1957 & $\begin{array}{l}\text { Hemphill ve Co- } \\
\text { ons }\end{array}$ & $\begin{array}{l}\text { Bir örgütün eylemlerini ortak bir amaca doğru yönlendiren bi- } \\
\text { reysel davranışların tamamıdır. }\end{array}$ \\
\hline 1978 & Katz ve Kahn & $\begin{array}{l}\text { Örgütün sıradan faaliyetleri ile ortaya çıkan ve otomatik bir } \\
\text { uyum ve bu uyumun daha da fazlası olan etkili bir büyümedir. }\end{array}$ \\
\hline 1986 & Richards ve Engle & $\begin{array}{l}\text { Örgütün, vizyonunu tanımlanmasına ve sahip olduğu değerle- } \\
\text { rini somutlaştırabilmesini sağlayacak bir ortam oluşturabilme- } \\
\text { sidir. }\end{array}$ \\
\hline 1994 & Drath ve Palus & İnsanların birlikte neler yaptığını anlama sürecidir \\
\hline 2010 & Koçel & $\begin{array}{l}\text { Belirli şartlar altında, önceden belirlenmiş kişisel veya örgütsel } \\
\text { amaçları gerçekleştirmek üzere başkalarının faaliyetlerini etki- } \\
\text { leme ve yönlendirme sürecidir. }\end{array}$ \\
\hline
\end{tabular}

Yukarıda tarihin farklı zamanlarında yapılan liderlik tanımlarından da anlaşılacağı üzere değişen ve gelişen koşullara bağlı olarak liderlerin üstlendiği rol ve sorumluluklarda değişime uğramıştır (Akgemci, 2008, s.511). Dolayısıyla liderlik yıllar içinde farklı formlara girmiş ve geleneksel yaklaşımların yanında günümüz çalışma hayatının ihtiyaçlarına cevap verecek farklı ve yeni liderlik yaklaşımları ve tanımları ortaya çıkmıştır (Gelatt 2002). Ancak kavramla ilgili literatürde pek çok teorik ve ampirik 
çalışma yapılmasına rağmen, henüz liderliğin tanımı ile ilgili üzerinde fikir birliğine varılmış net bir tanımı bulunmamaktadır (Bass, 1990, s.18). Bu durumun sebebi olarak, insanlık tarihinin her döneminde her durum ve koşula göre değişen türde lider ve lider özelliklerinin ortaya çıkması, (Buluç, 1998, s.2), örgütlerin faaliyette bulunduğu çevrenin dinamik yapısına bağlı olarak sürekli ve hızlı bir değişim yaşaması, insan faktörünün değişken, öngörülemeyen ve karmaşık bir yapıya sahip olması (Akgemci, 2008, s.512) gibi nedenler gösterilebilir.

Liderliğin temel işlevi; önceden belirlenmiş olan bireysel ve örgütsel amaçlara ulaşmak için, izleyenlerinin gönüllü katılımını sağlayabilmektir (Kreitner, 1989, s.511). Ayrıca liderlik sürecini doğru ve etkili yöneten liderler, izleyenlerine güç vermekte ( Mawell, 195, s.193), örgütüne veya topluma vizyon aşılamakta fırsat ve yeni alternatifler yaratarak sorunların açığa çıkmasına yardımcı olmakta, moral ve motivasyon seviyesini yükselterek örgütlerde birlik olma duygusunu aşllamakta izleyenlerine ilham vererek geleceğe ilişkin bir vizyon oluşturmaktadır (Pfeffer, 1981: s.231; Akıncı, 1998, s.102). Kısaca liderlik, hem sosyal hem de işlevsel bir süreci ifade etmektedir (Koçel, 2010, s.466).

\section{Resonant (Ahenk Yaratan) Liderlik}

İçinde bulunulan çevrenin sürekli olarak değişmesi, bilgi seviyelerinin artması, sosyo-kültürel, ekonomik gelişmeler ve teknolojinin ilerlemesi eskiye oranla daha hızlı bir şekilde yaşanmaktadır (Benjamin ve Flynn, 2006: 217). Bu gelişmelerle birlikte günümüz insanı, örgütler ve özellikle de karar verici konumunda olan liderler daha istikrarsız, daha belirsiz ve daha karmaşık bir ortamla karşı karşıyadır. Ancak tüm bu değişimler belirsizlik kadar fırsatları da içermektedir. Örgütlerin bu firsatlardan yararlanabilmesi için (Boyatzis ve McKee, 2005, s.594) etkili liderlik tarzlarına ihtiyacı vardır (Uhl-Bien, 2006, s.654-676). Temeli duygusal zekaya dayanan resonant liderlik bu tarzın bir örneğidir.

Resonant liderlik duygusal zeka üzerine temellendirilmiş bir kavramdır ve bu yönü ile diğer liderlik tarzlarından da ayrılmaktadır (Goleman, Boyatzis ve McKee, 2002). Duygusal zeka kavramı öz-farkındalık (kendi duygularını gerçekleştirme, güçlü yanlarını ve sınırlamalarını bilmek), öz- 
yönetim (duygularını kontrol edebilme, esneklik ve uyarlanabilirlik), sosyal farkındalık (empati), ilişki yönetimi gibi konuları kapsamaktadır (Boyatzis ve McKee, 2005, s.594). Duygusal zeka seviyesi yüksek olan liderler, kendilerini tanıma ve yönetme yeteneklerinin yanında, diğer insanların duygularını yönetir ve onlarla güçlü ve güvenilir ilişkiler kurarlar.

Resonant liderler duyguların bulaşıcı olduğu ve kendi duygularının başkalarının duygularını ve dolayısıyla onların performansını etkiyeceğinin farkındadırlar (McKee ve Smith, 2006, s.26). Bu tür liderlerin empati yapabilme yetenekleri daha üst seviyededir. Olaylara ve konulara farklı perspektiflerden bakarak topladıkları bilgilere göre davranmaktadırlar. Ayrıca resonant liderler, başkaları ile işbirliği yapmaya, kendileri geliştirmek için adımlar atmaya ve davranışlarını değiştirmeye de hazırdırlar.

Kökeni resonant kavramına (sesin titreşimle yoğunlaşması ve uzaması anlamina gelen) dayanan resonant liderler (Boyatzis ve McKee, 2005, s. 594) etkileşimde bulundukları çalışanları ile uyum içerisinde oldukları sürece belirlenen amaçlara yoğunlaşarak, amacın gerçekleşmesi için olağanüstü çaba gösterirler (Lutzo, 2005). Bu bağlamda resonant liderler bu süreçte beraber çalıştıkları insanlarla iyi iletişim kurarlar, bu da, liderin izleyenleri ile uyum içinde çalışmasını ve neyi ne zaman ve neden yapacakları konusunda fikirlerini paylaşmasını yardımcı olan bir unsurdur (Boyatzis ve McKee, 2005, s.595).

Resonant liderlik, " insanların hislerine uyum sağlamış ve onları olumlu duygusal yönde harekete geçiren liderlik" olarak tanımlanmaktadır (McKee ve Massimilian, 2006, s.45-49, Demirtaş ve Akdoğan, 2014, s.643). Bu tür liderler, çevreleriyle uyumludur, bu da ekip üyeleri arasındaki duygu ve düşüncelerinin uyumu ile sonuçlanmaktadır. Resonant liderler, aynı zamanda güçlü ve güvene dayalı ilişkiler kurarken, yalnızca kendi duygularını değil, liderlik yaptıkları insanların duygu ve düşüncelerini de kontrol edebilme gücüne sahiptirler (Boyatzis ve McKee, 2005, s.597). Resonant liderler, tutkulu, kararlı ve örgütleri doğru şekilde okuma becerisine sahiptirler. Ek olarak bu liderler yeni ve heyecan verici bir geleceğe doğru ilerlerken umutlu, cesaretli (Boyatzis, 2008), açı görüşlü ve pozitif düşünce gücüne sahip olduklarından izleyenlerine ilham vermektedirler (Taner, 2013, s.596).

Resonant liderlik yaklaşımında, örgütlerde etkili bir performans elde etmek için, liderlerin finansal, sosyal ve entelektüel sermayeyi etkili bir 
şekilde harmanlaması ve gerekli olan teorik ve pratik bilgiye sahip olması önemlidir. Diğer önemli bir nokta, liderlerin piyasaları şekillendiren faktörleri, teknolojinin hangi düzeyde olduğu ve etkileri, çalışanları ve örgütleri etkileyen diğer faktörleri de bilmesi ve anlaması gerekmektedir. Bununla birlikte, bu bilgilerin bilinmesi etkili ve sürdürülebilir bir liderlik için yeterli değildir. Bu noktada liderlerin bu bilgileri uyumlu bir şekilde uzmanlık ve tecrübelerini de kullanarak örgütlerin performansı için kullanımını sağlaması gerekmektedir. Gerekli bilgilerin yönetim süreçlerinde uyumlu bir şekilde kullanımı liderler ve diğer örgüt üyelerinin arasındaki dayanışma duygusunun güçlenmesine de katkı sağlayacaktır (Boyatzis and McKee, 2005, s.596).

Ancak günümüzün zorlu, stresli, karmaşa ve kaos barındıran Dünyasinda resonant liderlik becerilerinin oluşması ve sürdürülebilir hale getirilmesi oldukça zordur. Çoğu zaman liderler bu durumdan olumsuz etkilenmekte ve bu becerilerin sürekli hale gelebilmesi için liderlerin pek çok konuda fedakârlık yapması gerekmektedir. Zorlu koşullara ve uzun çalışma saatlerine rağmen bu durumun üstesinden gelmek isteyen liderlerin kendini fark etmesi ve bu sürece zihinsel, bedensel ve ruhsal olarak kendini hazırlaması gerekmektedir (McKee and Smith, 2006, s.26).

\section{Resonant Liderlik ile İlgili Yapılmış Çalışmalar}

Çalışma konusu olarak belirlenen Resonant (Ahenk yaratan) liderlik ile ilgili literatürde yapılan çalışmalar Tablo 2'de verilmiştir. Belirtilen araştırmalar, değişkenlerin sıralaması ve bu sıralamada tarihi kronolojiye göre sıralanarak verilmiştir. Söz konusu araştırmalar, araştırmanın tarihi, araştırmayı yapan kişi, makalenin adı ve makalenin katkısı şeklinde tablo 2' de yer almaktadır. 
Tablo 2. Resonant Liderlik İle İlgili Yapılmış Bazı Çalışmalar

\begin{tabular}{|c|c|c|c|}
\hline \multicolumn{4}{|c|}{ Resonant (Ahenk yaratan) Liderlik } \\
\hline Y11 & Yazarlar & Yayın adı & Katkisı \\
\hline 2005 & $\begin{array}{l}\text { Boyatzis, R. } \\
\text { E. ve McKee, } \\
\text { A. }\end{array}$ & $\begin{array}{l}\text { Resonant Lead- } \\
\text { ership: Renew- } \\
\text { ing Yourself } \\
\text { and Connecting } \\
\text { with Others } \\
\text { through } \\
\text { Mindfulness, } \\
\text { Hope, and } \\
\text { Compassion. }\end{array}$ & $\begin{array}{l}\text { Resonant liderlik kavramını araştırmaya } \\
\text { başlayan ilk çalışmalardan biridir. Çalışmaya } \\
\text { göre resonant liderler duygusal zeka seviyesi } \\
\text { yüksek, bireylerarası ilişkiler üzerine temellen- } \\
\text { dirilmiş ve iletişime açı, uyumlu, empati yapa- } \\
\text { bilen ve bunlara benzer bir çok olumlu beceriyi } \\
\text { taşıan bireyler için kullanılan kavramdır. Bu } \\
\text { kavram üç unsurdan oluşmaktadır. Bunlar; } \\
\text { farkındalık, umut ve merhamettir. }\end{array}$ \\
\hline 2010 & $\begin{array}{l}\text { Squires,M. } \\
\text { Tourangeau, } \\
\text { A. Lachinger, } \\
\text { H.K.ve } \\
\text { Doran,D. }\end{array}$ & $\begin{array}{l}\text { The link } \\
\text { between } \\
\text { leadership and } \\
\text { safety } \\
\text { outcomes } \\
\text { in hospitals }\end{array}$ & $\begin{array}{l}\text { Resonant liderliğin, hemşireler arasındaki düşük } \\
\text { duygusal tükenmişlik ve işten ayrılma niyetle- } \\
\text { rinin yanı sıra yüksek kaliteli liderlik ilişkileri, } \\
\text { iyileştirilmiş güvenlik ortamları ve destekleyici } \\
\text { mesleki uygulama ortamları ile önemli ölçüde } \\
\text { ilişkili olduğunu bulmuşlardır. Bu çalışma, reso- } \\
\text { nant liderlik ölçeğinin kabul edilebilir güvenil- } \\
\text { irliğini ve geçerliliğini gösteren ilk çalışmalardan } \\
\text { biridir. }\end{array}$ \\
\hline 2014 & $\begin{array}{l}\text { Laschinger } \\
\text { Spence,H.K. } \\
\text { Wong, C.A. } \\
\text { Cummings, } \\
\text { G.G. ve Grau, } \\
\text { A.L. }\end{array}$ & $\begin{array}{l}\text { Resonant Lead- } \\
\text { ership and } \\
\text { Workplace Em- } \\
\text { powerment: } \\
\text { The Value of } \\
\text { Positive Organi- } \\
\text { zational Cul- } \\
\text { tures in Reduc- } \\
\text { ing Workplace } \\
\text { Incivility }\end{array}$ & $\begin{array}{l}\text { Çalışmanın bulguları şunlardır; } \\
\text { (a)Resonant liderliğin personel güçlendirme } \\
\text { üzerindeki etkisini araştıran çalışmanın } \\
\text { sonuçlarına gore, resonant liderliğin personel } \\
\text { güçlendirmeyi olumlu anlamda etkilediğini } \\
\text { söylemek mümkündür. } \\
\text { (b)Ek olarak olumlu ve destekleyici liderlik mod- } \\
\text { elleri ile iş tatmini, duygusal tükenme arasında } \\
\text { negatif; örgütsel bağlllık ile pozitif bir ilişkiden } \\
\text { bahsetmek mümkündür. }\end{array}$ \\
\hline 2014 & $\begin{array}{l}\text { Demirtaş, Ö. } \\
\text { ve Akdoğan, } \\
\text { Asuman A. }\end{array}$ & $\begin{array}{l}\text { Resonat (Ahenk } \\
\text { Yaratan) } \\
\text { Liderlik Dav- } \\
\text { ranışlarının } \\
\text { Bireyin İşe } \\
\text { Adanmışlı̆̆ı } \\
\text { Üzerindeki } \\
\text { Etkisi: } \\
\text { Algılanan Mi- } \\
\text { zahın Düzen- } \\
\text { leyici Rolü }\end{array}$ & $\begin{array}{l}\text { Bu çalışmada, çalışma hayatında daha çok ahenk } \\
\text { yaratıcı bir tarzı benimseyen resonant liderlik } \\
\text { davranışlarının bireylerin işe adanmışlığına olan } \\
\text { etkisi ve bu süreçte mizah alfılamalarının aracı } \\
\text { rolünün olup olmadığı araştırılmıştır. Elde edilen } \\
\text { sonuçlara göre resonant liderlik davranışlarının } \\
\text { bireylerin işe adanmışlı̆ üzerinde anlamlı ve } \\
\text { pozitif bir etkiye sahip olduğu, ilave olarakta mi- } \\
\text { zah algılamasının bu etkide düzenleyici bir role } \\
\text { sahip olduğu söylemek mümkündür. Bu } \\
\text { sonuçlar, liderlerin davranış tarzlarının çalışanlar } \\
\text { için önemli bir faktör olduğunu göstermektedir. }\end{array}$ \\
\hline
\end{tabular}




\section{Resonant Liderliğin Boyutları}

Yapısı itibariyle kompleks sorunların yaşandığı günümüz bilgi çağında, sorunların çözümünde resonant liderlik yaklaşımının çıkış yollarından biri olduğu düşünülmektedir. Resonant (ahenk yaratan) liderlik yaklaş1mında, liderler krizi fırsata çevirerek korku ve umutsuzluk karşısında umut yaratmakta, güçlü ve tutkulu tavırları ile insanları harekete geçirmeyi başarabilmektedirler. Bu liderler, özellikle son dönemlerde oluşturdukları vizyoner yaklaşımlar ile imkansız olan hayalleri gerçekleştirmek için örgütlere ve toplumlara ilham vermektedirler. Yapılan araştırmalar bu tür liderlerin üç özellikleri ile bu vizyonu oluşturduğunu göstermektedir. Bu özellikler; farkındalık, umut ve merhamettir (Boyatzis ve McKee, 2002, s.16).

\section{Farkındalık}

Günümüz çalışma hayatında liderlere olan güvenin sarsılmasıyla birlikte kendi kişisel çıkarlarını bir tarafa bırakıp izleyenlerin ve örgütün gelişimine önem veren ve etkin liderlik davranışları sergileyen liderler odak noktası haline gelmiştir (Boyatzis and McKee, 2005, s.597). Etkin liderlik davranışlarının göstergelerinde biri olan duygusal farkındalık ve duyguların yönetilebilmesi, dönüşümcü liderliğin en son örneklerinden olan resonant liderliğin boyutlarından birisidir (Sartorius, 1999; Moss, 2001). Bu bağlamda, resonant liderlikte bireylerin öncelikle kendi duygularının farkında olması (öz-farkındalık) sonrasında ise sosyal farkındalık (empati) düzeylerinin önemi gittikçe artmıştır. Farkındalık kavramının anlamı ise; bireylerin ya da liderlerin kendisi, çevresi ve işi için eksiksiz ve bilinçli bir bir düzey geliştirerek bireylerin hayatlarını sürdürmesidir. Bu bağlamda bireyin kendisini ve dünyayı açıkça algılayarak anlaması örgütsel başarıya katkı sağlayan unsurlardan birisi olacaktır (Boyatzis and McKee, 2005, s.597).

\section{Umut}

Resonant liderliğin ikinci boyutu olan umut ise, belirlenen hedeflerin ger- 
çekleşebileceğine olan inançtır. Hedefleri gerçekleştirilmeye çalışılırken liderlerin bu konudaki umut düzeyinin yüksek olması izleyenleri de etkilemektedir. Umut düzeyi yükseldikçe liderler izleyenlerine ilham vermekte ve onları daha fazla motive etmektedirler (Boyatzis and McKee, 2005 , s.10). Böylece, çalışma hayatında umutlu ve ilham verici olmak, bireylerin daha iyi ve ulaşılabilir bir gelecek hayali kurulabileceğine olan inancını daha da artmaktadır.

\section{Merhamet}

Resonant liderliğin üçüncü boyutu olan merhamet; insanlık tarihi boyunca birçok din ve filozofun üzerinde durduğu bir kavram olmuştur (Kanov, Jason, Maitlis, Worline, Dutton, Frost ve Lilius, 2004, s.; Frost, Peter, Dutton, Maitlis, Lilius, Kanov ve Worline 2005, s.845; Lilius, Kanov, Dutton, Worline and Maitlis, 2011, s.5). Merhamet, bireylerin duyguların, başkalarının istek ve ihtiyaçlarını anlayarak düşünme, karar verme ve hareket etme sürecine dahil etmelerine yardımcı olan bir duygudur. Resonant liderler bu süreçte daha çok kendilerini başkalarının yerine koyarak onların duygu ve düşüncelerini doğru bir şekilde anlamaya gayret ederek kurarlar (Boyatzis and McKee, 2005, s.598). Bu özellik, günümüzün maddeci ve bireyselleştirilmiş dünyasında, herkesin ihtiyacı olan bir duygudur. Bu nedenle hem bireysel hem de örgütsel açıdan merhametin önemi giderek artmaktadır (Taner, 2013, s.595).

\section{Sonuç ve Tartışma}

İnsanlık tarihinin her döneminde olduğu gibi günümüz ve gelecekte de liderler, hayatın tüm alanlarında topluma yön vermeye devam edecektir. Bilginin hızla çoğalmasından, yayılmasından ve kendini yenilemesinden kaynaklanan değişim, lider kavramını da etkilemiş ve yeni liderlik formlarının ortaya çıkmasına neden olmuştur (Kırmaz, 2010, s.219). Bu değişim ve sonuçları sadece liderlik kavramını değil yönetim felsefesini de etkilemiş ve küresel boyutta ortaya çıan gelişmeler, örgütlerin yeni ve bu duruma uygun liderlik yaklaşımlarını bulmasını gerekli kılmıştır. Dolayısıyla, gerek kuramsal gerekse örgütsel alanlardaki liderlik çalışmalarının 
önemi gittikçe artmış ve örgütsel başarı için geleneksel liderlik yaklaşımlarının yerine, yeni liderlik yaklaşımları bir gereklilik olarak ortaya çıkmıştır (Keyman, 1995, s.145).

Bu yeni yaklaşımlardan biri olan ve temel kaynağı duygusal zeka olan "resonant liderlik" (ahenk yaratan liderlik) kavramı içerisinde farkındalık, umut ve merhameti barındırmaktadır. Bu üç özellik tüm liderlerde bulunması gereken özellikler olsa da resonant liderliği diğer liderlik türlerinden ayıran durum, liderlerin bu özellikleri duygusal zekalarını kullanarak yapabilmesidir (Lutzo, 2005; Taner, 2013, s.595). Bu çalışmada da, bugünden geleceği planlayan, amaçlar belirleyen resonant liderlik kavramı, Boyatzis ve McKee (2002)'nın teorisi ile uyumlu olarak ele alınmıştır. Bu kapsamda örgütlerin geleceğini şekillendirebilmek için duygusal zeka seviyesi yüksek, çevresiyle uyumlu, güçlü ve güvene dayalı ilişkiler kurabilen, sadece kendi duygularını değil, liderlik yaptığı izleyenlerinin duygu ve düşüncelerini de kontrol edebilme gücüne sahip liderlere ihtiyacı vardır. Bunun yanında örgütlerin; empati yapabilen, tutkulu, kararlı, umutlu, cesaretli, açık görüşlü, pozitif düşünce gücüne sahip, örgütleri doğru şekilde okuma becerisine sahip ve izleyenlerine ilham verebilen liderlere de ihtiyaç vardır.

Bu çalışmada özellikle yerli yazın açısından henüz istenen seviyelerde araştırılmamış vTürkçe kavramsal kullanımı da henüz geniş kabul görmemiş bir kavram olan, çalışma hayatında uyumlu ve ahenk yaratıcı bir yaklaşımı işaret eden resonant liderlik kavramının teorik olarak irdelenmesi amaçlanmıştır. Liderlik davranışları ve bu davranışların örgüt üyeleri üzerindeki olumlu yansımalarının bireysel ve örgütsel etkileri açısından önemli kazanımlar sağlayacağı kabul gören bir düşüncedir. Ancak her sosyal araştırmada olduğu gibi bu çalışmanın da bazı sınırlılıkları bulunmaktadır. Çalışmanın sadece teorik olarak irdelenmesi, bir araştırma ile desteklenmesi önemli bir konudur. Bu nedenle yapılacak değerlendirmeler belli bir noktada kalmaktadır. Bir bütün olarak kavrama yönelik bakış açısının detaylandırabilmesi için, kavramın araştırmalar ile desteklenmesi uygun olacaktır. Bu amaçla kavrama etki eden farklı değişkenleri konu alan araştırmaların yapılması örgütlere, topluma ve yöneticilere önemli ipuçları sunacaktır. 


\section{EXTENDED ABSTRACT}

\section{A New Leadership On The Knowledge Age: Resonant Leadership \\ Müslüme Akyüz \\ Sivas Cumhuriyet University}

It is a time when complexity and complex problems exist in the information age as its nature requires The need for effective leaders of organizations and new leadership approaches that want to gain a competitive advantage in the rapid change and transformation and in the solution of all these complexity and complex problems of the social, economic and technological developments is seen in this process at the work life. The existence of effective leaders in organizations always increases the success of organizations. Therefore, the concept of leadership has evolved over time and has reached a different level beyond classical leadership approaches. One of these new approaches is "resonant leadership". In this study, it is aimed to draw the limits of the concept by examining the sources in the local and foreign literature about the concept of resonant leadership as a new leadership model. For this aim, literature search method has been used.

Resonant leadership; it is possible to define it as having high level of emotional intelligence, beingcoherent with his/her environment, building strong and trustable relations, having power to control not only own feelings but also the feelings and thoughts of his followers, empathising, being passionate, determined, hopeful, courageous, open-minded, thinking positively, having the ability to read organizations correctly and inspiring his/her followers.

According to Boyatzis and McKee (2005), resonant leaders are believers, they conserve their values and live passionately. Resonant leaders communicate well with people they are working with, which enables them to work harmoniously and share their ideas and feelings about what to do and why to do. Leaders who can create resonance improve their emotional intelligence either instinctively or by working hard. In other words, they have improved themselves in issues such as self-awareness (realizing their own emotions, knowing their strong sides and limitations), self-management (being able to 
control their emotions, flexibility and adaptability), social awareness (empathy, organizational interest and responsibility) and relationship management.

In addition to the ability to know and manage themselves, emotionally intelligent people manage other people's emotions and have strong and dependable relationships with them. They know that emotions are contagious and their own emotions affect others' emotions and accordingly their performance. They are aware that people can be activated by fear or anger, but this type of activation will not be effective in the long term and the employees will feel less worthy, and hence will create an organizational climate in which they do not focus on organizational targets effectively.

Inability to achieve resonance leads to dissonance, that is, distress, crisis, internal disquiet, volatile emotions and unrest in organizations and among staff. Leaders who sustain resonance have the ability to consciously renew themselves through mind, body, heart, and spirit in a holistic process. Thus, resonant leaders show concern, resolve conflicts, are easily accessible, and enable staff growth and development, and these behaviours contribute to positive work

Resonant leadership has three dimensions which will be discussed in the following sections: mindfulness, hope and compassion. Actually it can be thought that all leaders must somehow possess these features. But the feature that distinguishes resonant leaders from others is being able to use these through their emotional intelligence. Three dimensions actually spark physiological changes that help to reverse the negative effects of power stress. By mindfully attending to oneself and others, encouraging an optimistic vision of the future, and caring for others, leaders can ignite resonance in themselves and those around them. Mindfulness, hope, and compassion enable resonant leadership and these same experiences enable renewal, which allows leaders to sustain their effectiveness. Then others catch it and become excited, creative and energised to be resilient, adaptive, and their best.

In this study, the concept of resonant leadership is discussed from an organizational point of view and which features it should have. As a result of the study, it has been determined that resonant leadership is an important leadership style which will find a place not only in the present but future.

\section{Kaynakça / References}

Akgemci, T. (2008). Stratejik yönetim. Ankara: Gazi Kitapevi. 
Akınc1, Vural B. (1998). Kurum kültürü ve örgütsel iletişim. İstanbul: İletişim Yayıncılık A.Ş.

Barutçugil, İ. (2014). Liderlik. İstanbul: Kariyer Yayıncılık.

Bass, B.M. (1990). Bass E Stogdill's handbook of leadership, theory, research, and managerial applications. (3.Edt), New York:The Free Press.

Benjamin, L. ve Flynn, F. J. (2006). Leadership style and regulatory mode: Value from Fit, Organizational Behaviourand Human Decision Processes. 100 (2), 216-230.

Boyatzis, R.E. ve McKee, A. (2002). Inspiring others through resonant leadership. Business Strategy Review, 17(2), 15-18. Doi:10.1111/j. 09556419.2006.00394.x

Boyatzis, R. ve McKee, A. (2005). Resonant leadership: Renewing yourself and connecting with others through mindfulness, hope, and compassion. Boston, MA: Harvard Business School Press.

Boyatzis, R.E. (2008). Competencies in the 21st century. The Journal of Management Development, 27(1), 5.

Buluç, B. (1998). Bilgi çă̆1 ve örgütsel liderlik. Yeni Türkiye 21. yy. Özel Sayısı, 20(4), 1- 13.

Cooley, H. C. (1902). Human nature and the social order. Cornell University Library.

Demirtaş, Ö. ve Akdoğan, A. (2014). Resonant (ahenk yaratan) liderlik davranışlarının bireyin işe adanmışlığı üzerindeki etkisi: Algılanan mizahın düzenleyici etkisi. (Ed. A. Öğüt), 22. Ulusal Yönetim ve Organizasyon Kongresi Bildiriler Kitabı içinde (s.642-647), 22-24 Mayıs 2014.

Dhammika, K. A. S. (2014). Visionary leadership and organizational citizenship behavior: An assessment of impact of sectarian difference. Proceedings of the First Middle East Conference on Global Business, Economics, Finance and Banking. (ME14 DUBAI Conference) Dubai, 10-12.

Drath, W. H. ve Palus, C. J. (1994). Making common sense: Leadership as meaningmaking in a community of practice, Greensboro, NC: Center for Creative Leadership.

Erçetin, Ş. (2000). Lider sarmalında vizyon. (2.Bsk), Ankara:Nobel Yayın Dağ1tım,

Frost, P. J., Dutton, J. E., Maitlis, S. L., Jacoba M. K., Jason, M. ve Worline, M. C. (2005). Seeing organizations differently: Three lenses on compassion. In (Ed. S. R. Clegg, C. Hardy, T. Lawrence and W. R. Nord), The Sage Handbook of Organization Studies, (p. 843-866). 2nd Ed 
Gelatt, J.P. (2002). Leadership. (Ed: Mann, C.J. ve Götz, K.). The Development of ManagementTheory and Practice in The United States, (65-86). USA: Pearson Custom Publishing.

Goleman, D., Boyatzis, R.E. ve McKee, A. (2002). The new leaders: Transform ing the art leadership of into the science of results, London, England: Little, Brown.

Hemphill, J. Coons, A. (1957). Development of the Leader Behaviour Description Questionnaire. (Ed. R.M.Stogill- A.E), Coons, Leader Behaviour: Its Description and Measurement, Colombus: Ohio State University.

Kanov, J. M., Maitlis, S. W., Monica, C., Dutton, J. E. F., Peter, J. ve Lilius, J. M. (2004). Compassion in organizational life. American Behavioral Scientist, (47), 808827.

Katz, D. ve Kahn, R.L. (1978). The social psychology of organizations (2nd ed.), New York: Wiley.

Keyman, F. (1995). Demokrasi, topluluk ve fark: Türkiye'deki liberalizm tartışmasına kuramsal bir katkı. Toplum ve Bilim, 66, 140-167.

Kırmaz, B. (2010). Bilgi çağı lideri. Ankara Barosu Dergisi, 68(3), 207-222. Koçel, T. (2010). İ̧sletme yöneticiliği, İstanbul: Beta Yayınevi.

Kreitner, R. (1989). Management. (4. Bsm). Boston: Mifflin Company.

Laschinger-Spence,H.K., Wong, C.A. Cummings, G.G. ve Grau, A.L. (2014). Resonant leadership and workplace empowerment: The value of positive organizational cultures in reducing workplace incivility. Nursing Economics, 32(1), 5- 17.

Lilius, J. M. K., Jason, M. D., Jane, E. W., Monica C., ve Maitlis, S. (2011) Compassion revealed: What we know about compassion at work (and where we need to know more). Access on 15.11.2012. http://webuser.bus.umich.edu/janedut/Compassion/POSCompassion_Chapter_FINAL $\% 20 \% 281 \% 29$.pdf

Lutzo, E. (2005). Resonant Leadership. Weatherhead Coaches Corner. 2(11), 07.04.2019 tarihinde http://www.forwardthought.net/articles/20051117ResonantLeadership.pdf adresinden erişilmiştir.

Mawell, J. C. (1995). Başarı için stratejiler. (Ed. Do. Cüceloğlu) (Çev: İ. Güpgüpoğlu), İstanbul: Sistem Yayıncillk.

McKee, A. ve Smith. D. (2006). Resonant leadership in higher education. 13.03.2019 tarihinde http://www.universitybusiness.com/article/resonant-leadership-higher-education adresinden erişilmiştir. 
McKee, A. ve Massimilian, D. (2006). Resonant leadership: A new kind of leadership for the digital Age. Journal of Business Strategy, 27(5), 45-49.

Moss, M. T. (2001). Emotional determinants in health care executive management styles. Yayınlanmamış Doktora Tezi, Medical University of South Carolina, ABD

Munson, E. L. (1921). The management of men, New York: Holt.

Northhouse, P. G. (2001). Leadership: Theory and practice. (2nd Ed.) Sage Pubilcations INC: California.

Pfeffer, J. (1981). Powe in organization. Marshfield, Mass: PitmanPublihing Inc.

Richards, D. ve Engle, S. (1986). After the vision: Suggestions to corporate visionaries and vision champions. In (Ed. J. D. Adams,), Transforming leadership. Alexandria. Englewood cliffs, NJ: Prentive Hall.

Sartorius, M. (1999). Kadınlarda duygusal zeka. İstanbul: Varlık Yayınları.

Tourangeau, S. M., A. Lachinger, H.K. ve Doran, D. (2010). The link between leadership and safety outcomes in hospitals. Journal of Nursing Management, 18, 914-925. doi: 10.1111/j.1365-2834.2010.01181.x

Taner, B. ve Aysen, B. (2013). The role of resonant leadership in organizations. European Scientific Journal, Özel Say1, 594-601.

Tokay H.S., Deran, A. ve Arslan, S. (2010). Lojistik maliyet yönetiminde izlenebilecek stratejiler ve muhasebe eğitiminden beklentiler. XXIX. Muhasebe Eğitimi Sempozyumu, Alanya, 21-15 Nisan.

Uhl-Bien, M. (2006). Relational leadership theory: Exploring the social processes of leadership and organizing. The Leadership Quarterly, 17(6), 654676.

\section{Kaynakça Bilgisi / Citation Information}

Akyüz, M. (2019). Bilgi çağında yeni bir liderlik: Resonant (ahenk yaratan) liderlik. OPUS-Uluslararası Toplum Araştırmaları Dergisi, 14(20), 1819-1834. DOI: 10.26466/opus.580701 